\title{
The Trauma Within Our Knowledge Bundles: Indigenous Helpers Navigating Trauma in Social Work Education and Practice
}

\author{
Olivia Ryan-Schmidt* \\ University of Victoria \\ oryanschmidt@gmail.com
}

\begin{abstract}
Trauma holds a sacred space in the knowledge bundles of many Indigenous helpers, including myself. A knowledge bundle represents the knowledge that an individual holds within themselves. This bundle consists of experiential knowledge, knowledge shared through teachings, and knowledge received through genetic memory. This article explores the potential trauma Indigenous social workers may face prior to practice, within post-secondary programs, and during practice. The literature written by Indigenous helpers working alongside trauma in the field of social work provides incredibly valuable knowledge for current helpers, as well as for students just beginning their journey into the social work field. How might Indigenous helpers working within the field of social work care for the trauma they may carry within their own knowledge bundles? This article examines how Indigenous helpers prepare to work with trauma, how they may navigate trauma within practice, and what happens after re-stimulation of traumatic events.

Keywords: Indigenous; trauma; decolonization; post-secondary education; social work
\end{abstract}

\section{Introduction}

$\mathrm{I}$ ndigenous content in social work education has made significant shifts in the past decade. The acceptance and recognition of Indigenous approaches to social work is growing amongst post-secondary institutions across Canada (Baikie, 2009). However, these changes are taking place in historically oppressive institutions that continue to privilege Western values and ways of learning. Once Indigenous helpers enter into practice, they often reach for culture-based frameworks, but do not feel as though they have been taught to do so in a good way through Western education (Linklater, 2014).

Trauma can have many different symptoms. Some of these symptoms are more common than others, such as flashbacks and dissociation (Levine, 1997). However, the symptoms for intergenerational trauma can be more complicated and are generally less understood by the clinical field (Menzies, 2010). If these symptoms are not as well researched and understood by the medical world, it is possible that they will not be as readily accepted by social workers' and other Indigenous helpers' employers as having real effects on their practice and their personal well-being. Linklater (2014) describes Indigenous peoples as

\footnotetext{
*This work would not have been possible without the gentle and unwavering support of Dr. Billie Allan. I would also like to express my deep gratitude to Gillian Saunders, Kari Chew, and the anonymous reviewers who contributed to this piece with such kindness and care. And finally, a special thank you to my family and loved ones, who provided me with encouragement and guidance throughout this process.
} 
having "lived in a multi-traumatic context, meaning that the trauma is personal, collective and historical" (p. 133). This far-reaching context must be understood by organizations and individuals supporting Indigenous helpers.

Kathy Absolon (2009) describes a strong knowledge bundle of a helper as containing "knowledge of culture, community, colonialism and decolonization" (p. 192). Within this bundle there should also be "knowledge of Indigenous healing practices and protocols" (p. 192). In our knowledge bundles we carry teachings from experience, family, and formal education, and often the teachings from lived trauma. The contents of knowledge bundles inform the work that helpers do. We pull from our bundle in times of need, for guidance through challenges. This article draws on personal reflection coupled with insights from current research to explore how Indigenous post-secondary students in social work programs prepare to work alongside trauma in practice in a holistic and culturally appropriate manner. It also considers how Indigenous helpers might navigate this trauma within their knowledge bundles throughout their social work practice and personal lives.

\section{Situating Myself Within This Work}

I begin by situating myself within the research I have done and making my intentions of sharing this knowledge clear. I am of mixed Métis, Irish, Russian, and German ancestry. I was raised on the unceded territory of the Ktunaxa and Sinixt peoples in a town called Nelson, an area heavily exploited by deforestation and mining in the late nineteenth century. My roots on both sides of my family can be traced back to the prairies. The prairies hold much of my family's history and I feel very connected to the land there, but have never lived upon it. As a social work student at the University of Victoria, I have been a visitor on the territories of the Lekwungen and WSÁNEĆ peoples for four years. I am committed to continuously learning how to be a good visitor on these territories and know that this work is an ongoing journey with no finish date. As a Métis woman and social work student, I am deeply linked to the topic at hand. My motivations for entering into this work are rooted in my obligations to my fellow Indigenous helpers who are navigating trauma in their lives and work. I acknowledge my responsibility to the generations before me who helped to create the path I am on, and the generations yet to come. While entering into research, I am entering into a relationship with the knowledge that I interact with, and I have a responsibility to share this knowledge in a way that stays true to the intentions of its initial sharing.

It is important to me that I make clear that my intention in writing this paper is not to glorify or romanticize trauma in any way; instead, I hope to acknowledge the important role it plays in the work that social workers do as helpers. While making these intentions clear, it is also important for me to acknowledge the ways that trauma within Indigenous communities has been, and continues to be, discussed in mainstream media and literary works. There is a history of mainstream media outlets choosing to publish stories and articles that reinforce negative stereotypes regarding Indigenous Peoples, while shying away from stories that may challenge such stereotypes. This means that Indigenous stories surrounding trauma are loosely told to a predominantly white-settler population for entertainment. I acknowledge this history and make clear that this paper is not intended for eyes seeking entertainment. The voices shared in this paper predominantly come from Indigenous researchers and scholars, and, by sharing these voices, I aim to represent the powerful voices of Indigenous helpers holding trauma within their knowledge bundles.

\section{Indigenous Students Confronting Trauma in Post-Secondary Social Work Studies}

The history of social work in Indigenous communities is highly problematic and filled with hurt and pain (Sinclair, 2009). To ensure that this damage does not repeat itself, this history must be a cornerstone of current social work education. Having a deep understanding of not only social work history, but also the ongoing impacts of colonization, is vital for ensuring that past harms do not get repeated. Yet, 
for the Indigenous students in social work programs, this constant revisiting of colonial destruction can be challenging. Discussing the impacts of colonization on Indigenous communities can be heavy and exhausting heart work for Indigenous students. Indigenous students cannot close the book on these topics; the work follows them home when class has ended. Covering topics such as colonization in course content may cause Indigenous students to confront trauma that they may not be aware of.

Although this process of confronting trauma in post-secondary education can be challenging, the classroom can be a safe space for Indigenous students to discuss topics such as the impacts of colonization. Linklater (2014) describes post-secondary institutions that provide Indigenous-centred programs as having the ability to create "an environment where everyone is in recovery-recovery from colonization" ( $p$. 47). Covering these topics in a space with others processing similar feelings may better prepare Indigenous students to encounter challenging situations in the workplace. The act of creating community with other Indigenous students is a form of creating trauma-informed support groups. Having a community of support that understands the complex realities of being an Indigenous student in a social work program can be beneficial in navigating trauma in course content. Learning to create appropriate communities of support is a skill that has the potential to aid helpers in navigating future challenges in practice.

An important gap to highlight in post-secondary institutions is the lack of acknowledgement of knowledge gathering that takes place outside of the classroom (Linklater, 2014). Indigenous students often have to seek additional knowledge from knowledge keepers in the community to supplement the Western context provided in the classroom. This work can be time consuming, and, although it is an essential part of a helper's education, it is still not widely recognized in academia (Linklater, 2014). This can also be reflected in Indigenous educators within social work programs, with the work they do in community still not being recognized and valued by post-secondary institutions (Baskin, 2016). Work within the community looks different to each educator, but for Indigenous educators this may look like providing additional resources for Indigenous students outside of the institution, helping students to build connections within the community, and supporting students in countless other ways. Of course, many educators work tirelessly to support their students, but this work may look different for Indigenous educators and might be less understood by post-secondary institutions. If this important work that is crucial to both Indigenous students and educators is not being valued in academia, this sets a dangerous precedent of perpetuating colonizing practices in academic institutions. Continuing to incorporate Indigenous ways of knowing into the work that we create in the academic world is a powerful act of decolonization. The community connections that I have built throughout my educational journey have given me strength to continue my learning in the classroom and in the community.

Education has long been a tool used in the war to assimilate North America into Eurocentric ways of being (Dumbill \& Green, 2008). The Canadian government used the residential school system to assimilate and integrate Indigenous youth into Western society (Dumbill \& Green, 2008). This resulted in horrific numbers of Indigenous children being forcefully removed from their families and communities, exposing them to atrocious harms and long-lasting trauma. Though post-secondary education has the potential to create positive community for Indigenous students, it is also important to acknowledge that it has the possibility to (and indeed often does) cause harm. Post-secondary courses taught with an Indigenous focus are not always available, thus causing students to take courses still deeply rooted in practices that privilege Western knowledge. Navigating historically oppressive institutions, which indirectly encourage colonizing practices, can be traumatizing for Indigenous students. Educational environments that provide Indigenous students with culturally relevant content may help to create space for healing and growth within these institutions. Dumbill and Green (2008) suggest that in order for Indigenous knowledge to be represented in social work programs, the dominant Western system must first be disrupted. It is important to acknowledge that this work of shifting the dominant Western education system is being done by many remarkable Indigenous educators and advocates. 


\section{Personal Journey Alongside Trauma}

Being an Indigenous student in a helping field requires balancing Western knowledge and Indigenous knowledge within our knowledge bundles. My personal connection to this paper comes from the feeling that the trauma I have experienced in my own life is something that I should be ashamed of. I was made to believe by Western society that this trauma would hinder the work that I do and that it had no place in my knowledge bundle. I hold my hands up in gratitude to the brilliant Indigenous educators I have learned alongside throughout my journey. These educators have shared their own experiences and countless teachings, which has taught me how to best carry my own teachings in the work that I do.

Within my own bundle, I carry teachings and practices that help to keep me grounded. This knowledge is both old and new. All of this knowledge has been touched by colonization, and my journey to connecting with this knowledge has been challenging. I carry my sage and sweetgrass in this bundle, using these medicines when I need to cleanse. My beads and thread are also found in this bundle, tools I use to create beaded florals while connecting with my ancestors. Métis Peoples are known as the flower beadwork people, and these flowers have taught me lessons about perseverance and the importance of slowing down. The knowledges of these practices are key components of my knowledge bundle, but my bundle also contains less tangible contents. This includes the knowledge I have received through Western education, some of which I am in the process of unlearning. I also carry knowledge from my family, some knowledge that I have been explicitly taught, and other knowledge that I hold without ever really being aware of when I picked it up. My lived experiences have also contributed to the knowledge I carry in my bundle; these include experiences of joy as well as pain. My knowledge bundle is a reflection of who I am, what I have lived through, and what experiences have shaped me. As a Métis helper in the field of social work, I am aware I bring my own knowledge of trauma into the work that I do. This knowledge will, at times, make it impossible to disconnect from the work I do in my community. I believe this knowledge will be my strength in this work.

In my younger years, I was not yet able to fully grasp the idea of a knowledge bundle. During those years, I endured intimate partner violence, an experience that has shaped me and the life path I have taken. I carried this trauma and the knowledge that it gave me for many years, unsure of where to place it in my life. I had created a narrative within myself that this trauma would somehow negatively affect my work as a helper. This narrative was created with the assumption that I could not help others while working through my own trauma. During this time, I was growing my knowledge bundle, and I began to realize that all teachings and practices have a time and place. It took me time to understand how and when to reach for the teachings in my knowledge bundle. I now know when to reach for my sweetgrass and when it is time to put my beadwork down. Reclaiming these practices has given me strength. Writing these words is a part of my journey to understand how to care for and utilize the knowledge of trauma that I hold within my own knowledge bundle.

\section{Implications}

It can be expected that those in helper roles will still experience hardship in their lives. This hardship will take the form of challenging events during practice, as well as in their personal lives. For Indigenous practitioners, the line between workplace practice and personal life is often blurred. When helpers work in their own community, the work they do can often become personal. This reality of community connection raises the possibility of re-traumatization for Indigenous social workers working in their own communities (Absolon, 2009). Thus, it is critical to consider the following questions: How are Indigenous social workers supported within the organizations they work for? Do Indigenous and non-Indigenous organizations recognize the blurred lines between practice and personal trauma? 


\section{Implications for Social Work Practice}

An important step in preparing for possible trauma in the workplace is acknowledging the distinct challenges that Indigenous helpers face during practice (Burke, 2018). These challenges may include struggles such as balancing Western knowledge alongside Indigenous ways of being and navigating the dynamic relationships with members of their communities (Absolon, 2019). While working in an individual's home community, dual relationships may be tricky to manoeuvre and require creating boundaries that provide safety for both the helper and those seeking services (Absolon, 2019). Discussing the concept of trauma within practice opens the door to speaking freely about it, and therefore may help others feel more comfortable seeking help afterwards. If a community is created in a workforce that does not support discussions surrounding trauma in practice, the employee will not expect to be supported after re-traumatization has occurred.

The lack of recognition that Indigenous knowledge faces within post-secondary institutions can be mirrored in organizations in the workforce. Researcher Susan Burke (2018) conducted a study examining the experiences of nine Indigenous social workers working in the child welfare system. Burke (2018) found that although these practitioners accessed some support, such as counselling, through their workplace, many of them had worries surrounding confidentiality that kept them from regularly accessing these resources. This study also found that the practitioners sought additional support, such as outside counselling services, Elders, and programs designed for residential school survivors, at their own cost. The need for culturally relevant support to be available and recognized through the workplace is clear.

Having Indigenous voices represented in leadership roles in the workplace can help in creating spaces where Indigenous helpers feel supported (Burke, 2018). Representation in management roles is important. Indigenous social workers working within non-Indigenous organizations can feel singled out, and may face pressure to be a source of knowledge for others regarding Indigenous issues in practice (Burke, 2018). These expectations can create feelings of isolation and disconnection with co-workers, including those in management roles. If Indigenous voices were represented in leadership roles more consistently, this pressure may not be so individualized. Non-Indigenous individuals working in the social work field should be actively working towards having a strong understanding while working alongside and within Indigenous communities. With Indigenous helpers in leadership roles, there may be a greater potential for Indigenous approaches to practice to be more accepted as an expected part of social work practice.

The disparities in funding between Indigenous and government organizations is important to acknowledge when discussing support for Indigenous helpers. Many Indigenous organizations receive less funding in comparison to government-run organizations, and, as a result, have reduced access to resources (Burke, 2018). Although working in an Indigenous organization may help to foster a more supportive environment for Indigenous helpers, it can also be challenging due to potential lower wages and higher workload (Burke, 2018). If equal access to funding resources existed amongst these organizations, Indigenous helpers working within Indigenous organizations would be in a better place to succeed, and government organizations might feel increased pressure to incorporate better support for Indigenous helpers. If the wages were equal between Indigenous and non-Indigenous organizations, would this not help to create a more supportive environment for Indigenous helpers throughout the social work field?

\section{Implications for Indigenous Communities}

Indigenous helpers like me face a greater potential of exposure to re-traumatizing situations while working in their home community (Absolon, 2009). This interconnectedness that we feel with members of our community can help us to build trusting relationships with individuals we may be working with. The other side of these relationships is that when the community hurts, we do as well. The inability of helpers to separate self from community can create potential barriers when seeking help in the aftermath 
of re-traumatization. Who do helpers reach out to for help when they are usually the ones providing resources?

After a helper experiences a traumatic event, there is still significant stigmatization surrounding seeking help (Baskin, 2011). It can be challenging for helpers to reach out to their community and support system to ask for help. It is a role reversal in many ways, but one that is inevitable; we all need help at different times in our lives. Graham and Shier (2014) found that there is an overwhelming expectation for social workers to simply move on after trauma. These unspoken expectations can discourage individuals from speaking out and seeking help after becoming re-traumatized during practice. Breaking down Western societal norms that helpers face is the beginning of shifting the approach to providing support for helpers.

\section{Gaps in Services}

Through the research outlined in this paper, it is clear that there are gaps in the services available to Indigenous helpers in relation to trauma care at both an educational and workplace institution level. These gaps include the lack of Indigenous-focused social work programs, lack of discussions surrounding trauma within practice, and limited support for practitioners after re-traumatizing events occur. It seems as though there is a clear connection between the environment of post-secondary social work programs and the environment of the organizations employing Indigenous helpers. Indigenous helpers must feel safe in their organizations in order to safely work alongside trauma in their practice. I believe that change must begin with the education system: if Indigenous helpers are supported in post-secondary institutions in a way that acknowledges both past trauma as well as potential, this sets a standard for organizations to continue with a high level of support and understanding. This may look like open dialog in the workplace about the potential of trauma within practice, clear support systems in place, and opportunities to further personal healing.

\section{Ending in a Good Way}

Through this research, I have reflected on my own journey in the beginning stages of entering into a role as a helper. I feel immense gratitude for the knowledge I have gained while engaging with this topic. A significant portion of this knowledge is rooted in stories of personal trauma, and it is my hope that I have remained true to my intentions of representing this knowledge in a good way. Carrière and Richardson (2017) state that "in an Indigenous worldview where everything is connected, it is impossible to believe that we do not change the things we have touched" (p. 33). I have touched this work and acknowledge that my worldview is woven throughout this paper.

Baskin (2011) describes the act of helping someone else through a trauma similar to one's own as having healing possibilities. I relate deeply to this idea. As someone with a history of intimate partner violence, I feel the immense benefits of sharing my story in an attempt to normalize these conversations surrounding violence. Speaking about my trauma continues to help me understand it and give it a purpose in my life that is decided by me, not my abuser. There were many years where I was not on speaking terms with my own trauma: I was angry, and I hid it. I wanted to detach it from my entire being, my body, my mind, and my spirit. I now accept this trauma as an important part of myself. I do not like using the term "working through" my trauma, as it implies that I will one day come out the other side trauma free. That is not my intention, nor do I think it is an achievable goal. I actively work alongside my trauma, and, because of this, I can draw on these teachings of trauma from my own knowledge bundle. This is not easy. There are days I do not want to draw on these teachings of trauma, or simply cannot. That is the beauty of our knowledge bundle: we get to choose when and what to pull. I find that the more I learn from my trauma, the more I am able to reach for its teachings within my bundle. I may not view 
The Arbutus Review • $2020 \bullet$ Vol. 11, No. 1 Special Issue on Indigenous Wellness •

https://doi.org/10.18357/tar111202019460

my trauma as a gift; however, I do see the role that it plays within my knowledge bundle as a gift, and I will continue on this journey of learning how to best care for this important part of my knowledge bundle as I navigate practice.

Looking backwards is an important part of our journey, so that we may familiarize ourselves with the way home (Absolon, 2011). Those in helper roles are often required to look to past experiences not only to help themselves get home, but to help others to see their own path back home. This article has shown that trauma has an important role in the knowledge bundles of Indigenous helpers. The knowledge shared here has highlighted gaps in services available to Indigenous helpers preparing for and working in the field of social work and has gestured towards decolonial pathways by which we can redress these limitations. Indigenous helpers working alongside their trauma continue to bring light to the necessary changes needed within education, as well as workplace support, and the post-secondary education system must learn to support Indigenous helpers in this vital work. 
The Arbutus Review • $2020 \bullet$ Vol. 11, No. 1 Special Issue on Indigenous Wellness • https://doi.org/10.18357/tar111202019460

\section{References}

Absolon, K. E. (2011). Kaandossiwin: How we come to know. Halifax, NS: Fernwood Publishing.

Absolon, K. (2009). Navigating the landscape of practice: Dbaagmowin of a helper. In R. Sinclair, M.A. Hart, \& G. Bruyere (Eds.), Wicihitowin: Aboriginal social work in Canada (pp. 172-199). Black Point, NS/Winnipeg, MB: Fernwood Publishing.

Baikie, G. (2009). Indigenous-centred social work: Theorizing a social work way-of-being. In R. Sinclair, M.A. Hart, \& G. Bruyere (Eds.), Wicihitowin: Aboriginal social work in Canada (pp. 42-64). Black Point, NS/Winnipeg, MB: Fernwood Publishing.

Baskin, C. (2016). Strong helpers' teachings: The value of Indigenous knowledges in the helping professions (2nd ed.). Toronto, ON: Canadian Scholars' Press.

Burke, S. (2018). Supporting Indigenous social workers in front-line practice. Canadian Social Work Review / Revue canadienne de service social, 35 (1), 5-25. https://doi.org/10.7202/1051100ar

Carrière, J., \& Richardson, C. (2017). Calling our families home: Métis peoples' experiences with child welfare. Vernon, BC: JCharlton Publishing.

Dumbrill, G. C., \& Green, J. (2008). Indigenous knowledge in the social work academy. Social Work Education, 27(5), 489-503. https://doi.org/10.1080/02615470701379891

Graham, J. R., \& Shier, M. L. (2014). Profession and workplace expectations of social workers: Implications for social worker subjective well-being. Journal of Social Work Practice, 28(1), 95-110. https://doi.org/10.1080/02650533.2013.810613

Levine, P. (1997). Walking the tiger healing trauma: The innate capacity to transform overwhelming experiences. Berkeley, CA: North Atlantic Books.

Linklater, R. (2014). Decolonizing trauma work: Indigenous stories and strategies. Halifax, NS: Fernwood Publishing.

Menzies, P. (2010). Intergenerational trauma from a mental health perspective. Native Social Work Journal, 7, 63-85. https://www.collectionscanada.gc.ca/obj/thesescanada/vol2/OSUL/TC-OSUL384.PDF

Simpson, L. (2014). Land as pedagogy: Nishnaabeg intelligence and rebellious transformation. Decolonization: Indigeneity, Education \& Society, 3(3), 1-25. https://jps.library.utoronto.ca/index .php/des/article/view/22170/17985

Sinclair, R. (2009). Bridging the past and the future: An introduction to Indigenous social work issues. In R. Sinclair, M.A. Hart, \& G. Bruyere (Eds.), Wicihitowin: Aboriginal social work in Canada (pp. 19-41). Black Point, NS/Winnipeg, MB: Fernwood Publishing. 